\title{
Cardio embolic stroke and blood biomarkers: diagnosis and predictors of short-term outcome
}

\author{
Wafaa S. Mohamed(D, Elhady A. Abd ElGawad, Amal SE. ElMotayam and Sabah E. Fathy
}

\begin{abstract}
Background: The brain is a productive source of a variety of enzymes and any brain injury like a stroke to brain tissue could similarly result in an increase in these enzymes in cerebrospinal fluid and serum. Evaluation of these enzymes represents a simple method for the ischemic stroke subtype diagnosis and prognosis. Objective: This study aimed to determine the role of brain natriuretic peptide (BNP), D-dimer, creatine-kinase-MB (CK-MB), C-reactive protein (CRP) serum levels, and globulin/albumin ratio in the diagnosis of CES stroke and its ability to predict short-term outcome.

Methods: This study was conducted on 96 patients with acute ischemic stroke, subdivided into two groups: group I was 48 patients with cardio-embolic stroke and group II was 48 patients with non-cardio-embolic. All patients were subjected to the assessment of serum BNP, D-dimer and CK-MB, and CRP and globulin/albumin ratio within the first 24 $h$ of stroke. In the third week, they were assessed by mRS.
\end{abstract}

Results: The mean levels of BNP, D-dimer level, and CK-MB were significantly higher in patients with cardio-embolic stroke than in patients with non-cardio-embolic stroke $(P<0.001)$ and also were associated with poor short-term outcome.

Conclusion: Elevated plasma levels of BNP, D-dimer levels, and CK-MB can be used as surrogate biomarkers for the diagnosis of cardio-embolic stroke and prediction of poor short-term outcomes.

Keywords: Cardio-embolic stroke, Biomarkers, Brain natriuretic peptide, D-dimer, Creatine kinase, MB, C-reactive protein, G/a ratio, Outcome

\section{Background}

Ischemic stroke is one of the most important neurological disorders [1]. An accurate pathogenic classification of ischemic stroke is essential to prescribe the secondary treatment to prevent recurrences [2]. Cardio-embolic stroke (CES) accounts for $20 \%$ of all ischemic strokes (IS) and is more restricting than non-embolic subtypes of stroke [3]. CES has the most unfavorable prognosis, being linked with an increased hazard of death or stroke recurrence [4].

Neurons is a rich source of a variety of enzymes, and any injury like stroke to brain tissue could similarly result in an increase in level of these enzymes in cerebrospinal fluid and serum. Evaluation of these enzyme levels

\footnotetext{
* Correspondence: Dr.wafaa74@yahoo.com

Department of Neurology, Faculty of Medicine, Zagazig University, Sharkia, Egypt
}

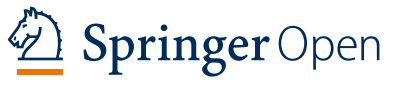

(c) The Author(s). 2019 Open Access This article is distributed under the terms of the Creative Commons Attribution 4.0 International License (http://creativecommons.org/licenses/by/4.0/), which permits unrestricted use, distribution, and reproduction in any medium, provided you give appropriate credit to the original author(s) and the source, provide a link to the Creative Commons license, and indicate if changes were made. may be an easily available method for the evaluation of severity, course, prognosis, and to some extent in the differential diagnosis of various subtypes of cerebrovascular accidents [5].

D-Dimer and brain natriuretic peptide (BNP) are reported as markers of active coagulation so higher levels reflect more coagulation and larger lesions [6]; D-dimer is the final fibrin degradation product of fibrin-rich thrombi, and its increase is an indicator of thrombus formation and lysis within the left atrium and is the key factor of cardiac embolism onset. Thrombus formation in the cardiac chambers is mainly due to blood stasis, leading to a fibrin-rich clot very similar to venous thrombi. Conversely, thrombi originating in the large arteries are mostly platelet rich, and fibrin formation is secondary to platelet activation [7]. 
Brain natriuretic peptide is a 32-amino acid polypeptide released primarily from cardiac ventricles on exposure to volume or pressure overload; the ventricular musculature secretes pre-pro-BNP, which is cleaved into a 108-amino acid pro-BNP, which is further cleaved into biologically active BNP (32-amino acid) and the inert NT-pro-BNP (76-amino acid). BNP causes natriuresis, vasodilation, and diuresis, all of which leads to improved myocardial relaxation [8].

Creatine-kinase-MB (CK-MB) as well has been found to be elevated in certain patients with IS, and this elevation was mainly attributed to dysfunction in the sympathetic nervous system due to increased intracranial pressure that induce tachycardia, coronary vasospasm, coronary and peripheral vasoconstriction, and direct myocardial toxicity due to increased intracellular calcium [9].

Elevated C-reactive protein (CRP) in IS subtypes is not clear, may be binding of CRP to phospholipids which are involved in the coagulation cascades and potentially activated by emboli from heart [10].

Different molecules also may behave differently in the pro-thrombotic conditions; albumin synthesis decreases, while other inflammatory globulins rise. Albumin and globulins variations could also be suggestive of a prothrombotic state, and globulin/albumin ratio (G/A) correlates with blood viscosity, being a high ratio associated with increased blood viscosity [11].

\section{Aim}

This study was to determine the role of BNP, D-dimer, CK-MB, CRP serum levels, and G/A ratio in CES diagnosis and prediction of short-term outcome.

\section{Patients' and methods}

This is a prospective study which was conducted on 96 AIS patients divided to two groups: group I: 48 patients with cardio-embolic stroke (CES) and group II: 48 patients with ischemic cerebrovascular stroke other than cardio-embolic stroke that include large artery atherosclerosis, small artery occlusion (lacunae), stroke of other determined etiology, and stroke of undetermined etiology (non CES) [12], with first-ever acute ischemic stroke within $24 \mathrm{~h}$ of onset of symptoms admitted to Intensive Care and Stroke Unit, Neurology Department, Zagazig University Hospitals, during the period from October 2015 to October 2018. Written informed consent was obtained from all patients or written assent from a relative.

\section{Inclusion criteria}

1. CES and non- CES diagnosis was according to Trial of Org 10172 in Acute Stroke Treatment (TOAST) classification criteria. CES include patients with cardiac source of emboli, at least one cardiac source for an embolus, must be identified for a possible or probable diagnosis of cardio embolic stroke.

Evidence of a previous systemic embolism supports a clinical diagnosis of cardiogenic stroke. Potential large-artery atherosclerotic sources of thrombosis or embolism should be eliminated. A stroke in a patient with a medium-risk cardiac source of embolism and no other cause of stroke is classified as a possible cardio embolic stroke [12].

2. Non-CES were selected to match patients with CES regarding age, sex, and stroke severity.

3. Patients with National Institutes of Health Stroke Scale (NIHSS) score more than 5.

4. Adult patients with their ages more than 18 year.

\section{Exclusion criteria}

This includes lacunar stroke and transient ischemic attacks (TIAs);hemorrhagic stroke; other neurological causes of acute focal cerebral dysfunction such as cerebral venous sinus thrombosis, head trauma, infection, and auto immune disorders; heart failure; liver failure; and chronic renal disease.

All patients were subjected to full-detailed neurological history with stressing on the vascular and cardiac risk factors and general and neurological examination. Glasgow Coma Scale (GCS) is used to detect the depth of coma [13], and stroke severity was assessed using the National Institutes of Health Stroke Scale (NIHSS) [14].

\section{Laboratory investigations}

Fifteen milliliters of venous blood was obtained from the patients within the first $24 \mathrm{~h}$ of stroke. All routine and special laboratory investigations were done at Clinical pathology department, Zagazig University Hospitals including $\mathrm{CBC}$, liver function, kidney function, ESR, and lipid profile.

\section{Brain natriuretic peptide}

Four milliliters of blood was placed in a polypro pane tube containing a mixture of sodium salt of ethylene diamine tetra acetic acid (EDTA) at a concentration of 1 $\mathrm{mg} / \mathrm{ml}$ of blood and aprotinin at a concentration of 500 kallikerin inhibitory unit (kiu)/ml of blood serving as a natural proteinase inhibitor which acts as a preservative for natriuretic peptides, then mixing of the blood was done. Then, the tube was centrifuged at $5000 \mathrm{rpm}$ for $15 \mathrm{~min}$ in the cool centrifuge, the separated serum was stored at $-70{ }^{\circ} \mathrm{C}$ until analysis.

Later on, the assay was done using human BNP Elisa kits (Spain react kits sr 19369u) which are immune-sorbent assays for quantitative measurement; the least sensitivity is $14 \mathrm{pg} / \mathrm{ml}$ and ranges from 14 to $1000 \mathrm{pg} / \mathrm{ml}$ [15]. 


\section{D-dimer}

Three milliliters of blood was collected within vacuum tubes containing $0.5 \mathrm{ml}$ buffered sodium citrate before the initiation of any oral, enteral, or parenteral feeding or medications. Blood samples were mixed well with avoiding of foam formation then immediately centrifuged at $3000 \mathrm{rpm}$ for $15 \mathrm{~min}$ at ambient room temperature, and the plasma is separated. D-Dimer was measured turbidmetry (SAT Liatest D-Di; Diagnostica STAGO) on the STAgo compact analyzer; normal value is less than $500 \mathrm{ng} / \mathrm{ml}$ [16].

\section{Creatine-kinase-MB}

Four milliliters of blood was derived within a plastic tube centrifuged at $4000 \mathrm{rpm}$ for $3 \mathrm{~min}$; the separated serum was assayed for CK-MB using Spain react kits with normal value up to $2.8 \mathrm{ng} / \mathrm{L}$ [17].

\section{C-reactive protein}

Four milliliters was withdrawn in a plastic tube centrifuged at $4000 \mathrm{rpm}$ for $3 \mathrm{~min}$, the separated serum used for analysis of CRP is measured using Olympus 640 analyzer with a normal value up to $5 \mathrm{mg} / \mathrm{L}$.

Globulin/albumin ratio (G/A) was calculated with normal ratio 0.6-0.7 [11].

All patients were evaluated by Brain CT or MRI for diagnosis of ischemic stroke.

Each patient underwent electrocardiogram, echocardiography, and carotid Doppler ultrasonography to define etiological stoke subtype.

The short-term outcome was evaluated in all patients at the third week of stroke onset using modified Rankin scale (mRS) ranging from zero (no symptoms at all) to 6 (dead). Outcome was defined as good if $\mathrm{mRS}=0-2$, bad (poor) if $\mathrm{mRS}=3-5$, and death if $\mathrm{mRS}=6$ [18].

\section{Statistical analysis}

Descriptive statistical methods were used to calculate means and standard deviation (SD). For comparisons with the continuous variables, Student's $t$ test was used. The sensitivity and specificity of biomarkers in diagnosis of CES and poor outcome prediction were also assessed by a receiver operating characteristic (ROC) curve. Logistic regression analysis was used to calculate the odds ratios (OR) and 95\% confidence intervals (CI) for risk estimation. A $p$ value of less than 0.05 was considered statistically significant. The data were tabulated and statistically analyzed using the software SPSS version 20 [19].

\section{Results}

We found that atrial fibrillation was the most prevalent cardiac source of thromboembolism with prevalence of $70.8 \%$ (34 out of 48 patients); AF was due to valve lesions in 29 patients and non valvular in 5 ones, followed by ischemic heart disease (35.4\%), prosthetic valve (20.8\%), and rheumatic heart disease (10.4\%), while hypertension and diabetes mellitus were the most common risk factors of non-CES as they present in $64.6 \%$ and $43.8 \%$ of non-CES patients, respectively, followed by smoking which is present in $35.4 \%$.

Regarding echocardiographic findings of CES patients, we found intra-cardiac thrombi in $6.2 \%$, ventricular wall motion anomalies in $29.2 \%$, mitral stenosis in $25 \%$, mitral regurge in $6.1 \%$, aortic stenosis in $2.1 \%$, aortic regurge in $4.2 \%$, multivalve lesions in $6.2 \%$, and cardiomyopathy in $27.1 \%$.

There are highly statistically significant differences between BNP, D-dimer, and CK-MB levels and type of stroke (cardio-embolic stroke) and non-significant differences between CRP, G/A ratio, and both stroke subtypes (Table 1).

Regarding the performance of different biomarkers in the prediction of cardio-embolic stroke (Table 2), we found that the best cutoff of BNP in prediction of CES is $\geq 69.5$, the sensitivity $75 \%$, specificity $62.5 \%$, and accuracy 68.8 with a highly significant effect (Fig. 1). The best cutoff of D-dimer in diagnosis of CES is $\geq 513$, the sensitivity $81.4 \%$, specificity 62.5 , and accuracy 71.4 (Fig. 2). The best cutoff of $\mathrm{CK}-\mathrm{MB}$ in diagnosis of CES is $\geq 0.95$, the sensitivity $85.4 \%$, specificity $75 \%$, and accuracy 80.2 (Fig. 3).

Our results (Table 3) illustrated that elevated levels of both CK-MB and CRP were reported in patients with poor short-term outcome compared with their levels in patients with good outcome, and this was a statistically significant difference ( $p=0.005$ and 0.02 , respectively). D-Dimer as well had a highly statistically significant role in predicting poor short-term outcome in CES patients $(p<0.001)$.

Table 4 demonstrated that BNP with a cutoff value of $\geq 89 \mathrm{pg} / \mathrm{ml}$ could predict the poor outcome in CES but this effect was with a statistically non-significant value $(p=0.764)$ (Fig. 4) and the best cutoff level of D-dimer in prediction of poor short-term outcome was $\geq 570 \mathrm{ng} / \mathrm{ml}$, and this value had a highly significant effect $(p<0.001)$ (Fig. 5). We noticed that the best cutoff level of $\mathrm{CK}-\mathrm{MB}$ in prediction of poor short-term outcome was $\geq 1.15 \mathrm{ng} / \mathrm{ml}$ and this was of a statistically significant value $(p=0.011)$ (Fig. 6) and the best cutoff of CRP in prediction of poor outcome was $\geq 25.5 \mathrm{mg} / \mathrm{l}$ and this value was of a significant effect $(p=0.021)$ (Fig. 7).

Studying the clinical and laboratory predictors of poor short-term outcome and good outcome in the patient group (with CES) showed that low GCS and elevated CK$\mathrm{MB}$ were the most important predictors of poor short-term outcome of CES patients at the third week as assessed by $\operatorname{mRS}(p=0.052$ and 0.044 , respectively) and high GCS and low NIHSS at admission were the best predictors of good outcome ( 0.019 and $<0.001$ respectively) (Tables 5 and 6). 
Table 1 A comparison of serum biomarkers levels in both patient groups

\begin{tabular}{|c|c|c|c|c|}
\hline Blood biomarkers & Group I (CES) & Group II (non-CES) & Test of significance( $t$ test) & $P$ \\
\hline \multicolumn{5}{|l|}{ BNP } \\
\hline Mean \pm SD $(\mathrm{pg} / \mathrm{ml})$ range & $134.6 \pm 93.3(100-420)$ & $68.33 \pm 12.69(50-95)$ & -5.046 & $<0.001^{* *}$ \\
\hline \multicolumn{5}{|l|}{ CK-MB } \\
\hline Mean \pm SD $(\mathrm{ng} / \mathrm{ml})$ range & $1.61 \pm 0.59(0.5-2.6)$ & $0.76 \pm 0.19(0.5-1)$ & 9.49 & $<0.001^{* *}$ \\
\hline \multicolumn{5}{|l|}{ D-Dimer } \\
\hline Mean \pm SD $(\mathrm{ng} / \mathrm{ml})$ range & $613.19 \pm 275.02(250-1090)$ & $277.92 \pm 80.16(100-500)$ & 8.109 & $<0.001^{* *}$ \\
\hline \multicolumn{5}{|l|}{ CRP } \\
\hline Mean \pm SD $(\mathrm{mg} / \mathrm{l})$ range & $28.72 \pm 26.31(5-100)$ & $34.91 \pm 27.39(5-109)$ & -1.129 & 0.262 \\
\hline \multicolumn{5}{|l|}{ G/A ratio } \\
\hline Mean \pm SD range & $0.73 \pm 0.04(0.63-0.79)$ & $0.71 \pm 0.06(0.62-0.79)$ & 1.369 & 0.175 \\
\hline
\end{tabular}

CES cardio-embolic stroke, non CES non-cardio-embolic stroke, BNP brain natriuretic peptide, CK-MB creatine-kinase, CRP C-reactive protein, G/A globulin/albumin **Statistically highly significant

\section{Discussion}

Brain natriuretic peptide (BNP) is secreted by the myocardium and the left atrium, so elevated levels may reflect increased cardiac chamber wall stress and/or intrinsic atrial disease [8]. In the current study, we found that BNP showed a highly statistically significant elevation when measured in the first $24 \mathrm{~h}$ in CES patients and the cutoff value of BNP in prediction of CES was 69.5 $\mathrm{pg} / \mathrm{ml}$; this was previously reported by Shizabaki and colleagues [20] who determined BNP cutoff value at 64 $\mathrm{pg} / \mathrm{ml}$ independently predict CES and Montaner and colleagues [7] who as well stated that BNP $>76 \mathrm{pg} / \mathrm{mL}$ indicated a Cardio-embolic etiology.

D-Dimer levels were found to be higher in CES with a mean level of $613.19 \pm 275.02$, and the cutoff value of $D$ dimer to be used as a biomarker for diagnosis of CES was $513 \mathrm{ng} / \mathrm{ml}$.

Different cutoff values of D-dimer were suggested as Sarhan and colleagues [16] determined a cutoff value of plasma D-dimer levels of $500 \mathrm{ng}$, while in other studies a higher cutoff value were noted as Doufekias and colleagues [21] who reported that D-dimer level of more than $1060 \mathrm{ng} / \mathrm{ml}$ indicates a high possibility of cardioembolic stroke, $\mathrm{Zi}$ and Shuai [6] reported a cutoff value of $910 \mathrm{ng} / \mathrm{ml}$, and lastly, Abd-Elhamid and colleagues [22] found that the cutoff value of D-dimer predicting cardio-embolic stroke was $1090 \mathrm{ng} / \mathrm{ml}$. On the contrary,
Zecca and colleagues [11] as well who found that Ddimer levels are the same among different stroke subtypes and could not be used as an indicator for CES. These results may be due to the selection of patients; there were patients with an embolic source in the aortic

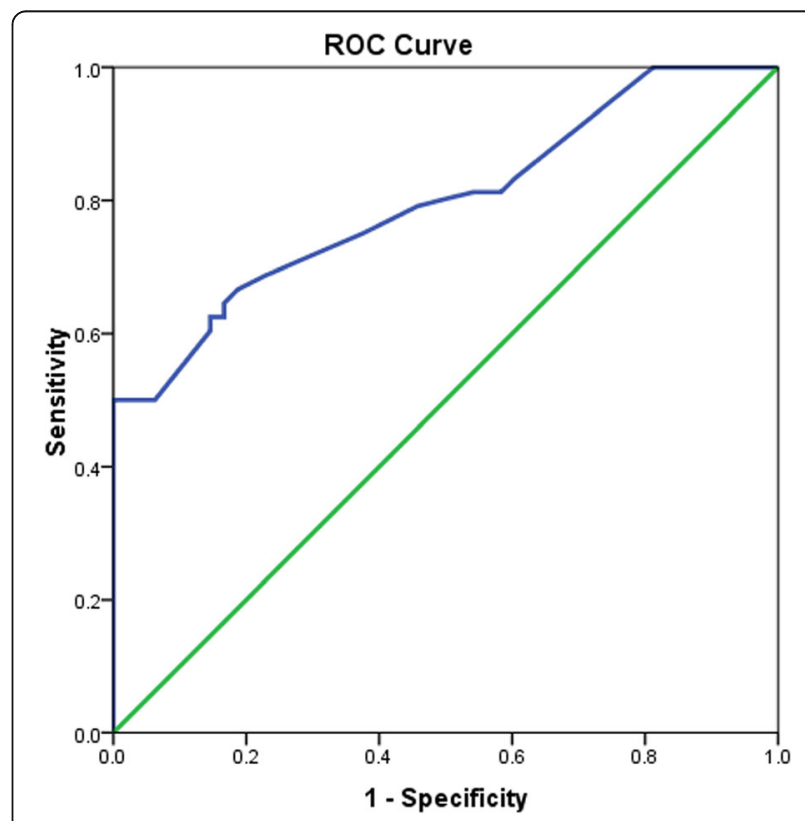

Fig. 1 ROC curve showing performance of BNP in diagnosis of CES

Table 2 The performance of different biomarkers in the prediction of cardio-embolic stroke

\begin{tabular}{lllllllll}
\hline Biomarker & Cutoff & AUC & Sensitivity & Specificity & PPV & NPV & Accuracy & $p$ \\
\hline BNP & 69.5 & 0.798 & 75 & 62.5 & 66.7 & 71.4 & 68.8 & $<0.001^{* *}$ \\
D-Dimer & 570 & 0.791 & 90.9 & 66.3 & 81.8 & 72.7 & 79.2 & $0.001^{*}$ \\
CK-MB & 0.95 & 0.907 & 85.4 & 75 & 77.4 & 83.7 & 80.2 & $<0.001^{* *}$ \\
\hline
\end{tabular}

BNP brain natriuretic peptide, $C K-M B$ creatine-kinase, $P P V$ positive predictive value, NPV negative predictive value **Statistically highly significant

*Statistically significant 


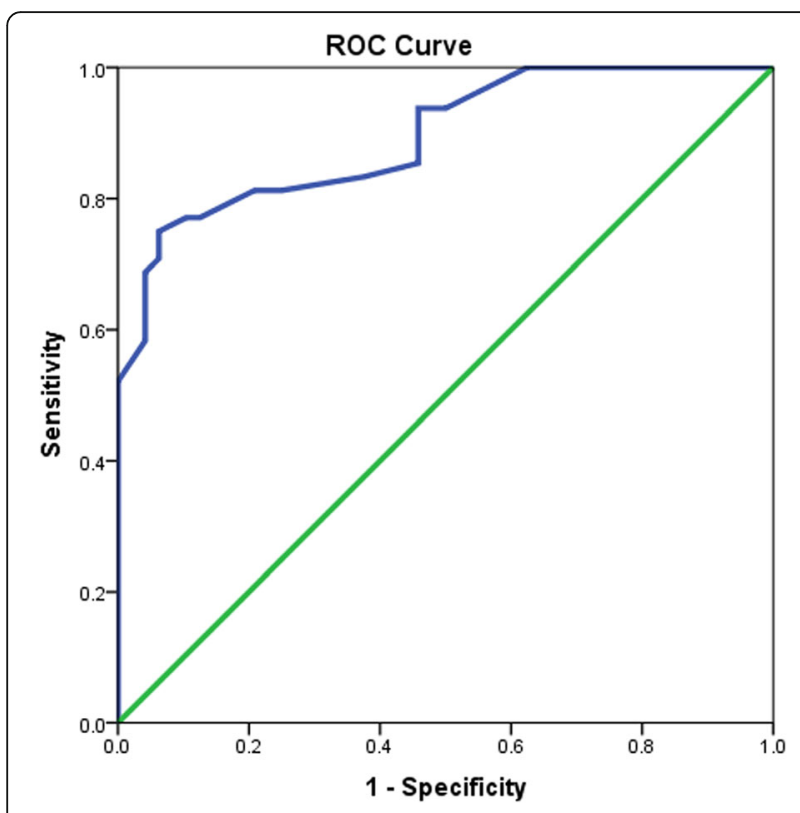

Fig. 2 ROC curve showing performance of D-dimer in diagnosis of CES

arch within the "embolic stroke" in which clots had a predominant platelet component, compared to clots of a cardio-embolic origin.

We also noted that CK-MB values were significantly higher among CES with a cutoff value of $0.95 \mathrm{ng} / \mathrm{ml}$.

Santamarina and colleagues [23] suggested that the CK-MB with a cutoff value $1.5 \mathrm{ng} / \mathrm{ml}$ could predict CES. This association was found in both patients with AF and patients with sinusal rhythm carrying other embolic

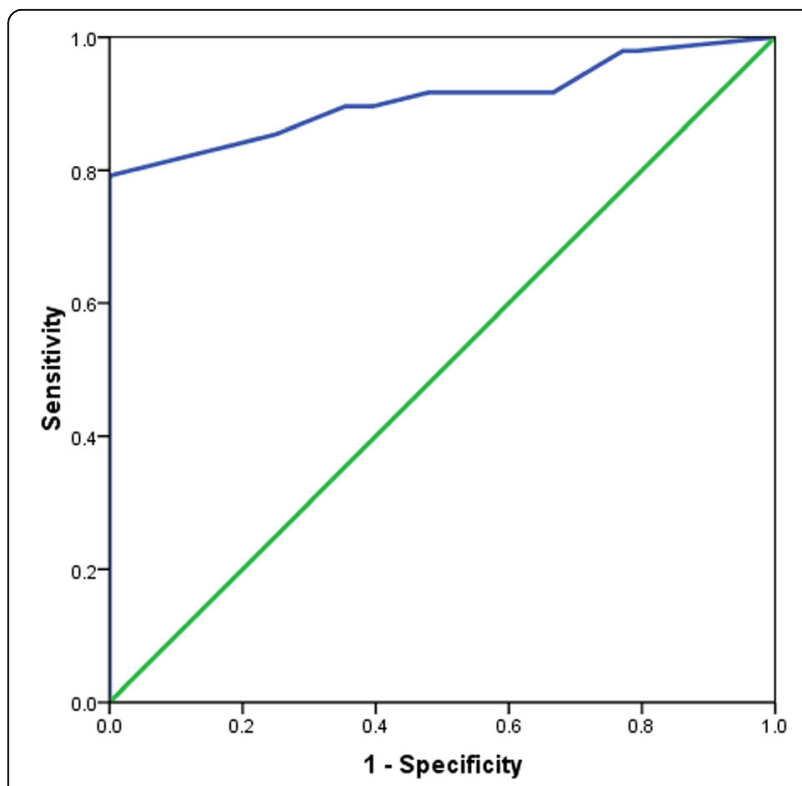

Fig. 3 ROC curve showing performance of CK-MB in diagnosis of CES findings. Rodriguez-Yanez and colleagues [24] as well found that cutoff point of CK-MB of $2.6 \mathrm{ng} / \mathrm{mL}$ could predict cardiac origin of ischemic stroke. On the other hand, Preethi and colleagues [5] as well noticed that CK$\mathrm{MB}$ is elevated in all stroke patients irrespective to its subtype and supposed that this rise in CK-MB levels are indicating that the origin of CK-MB is of brain related injury rather than cardiac origin. This difference may be due to the differences in the study design and the involved number of patients.

As regards CRP as a biomarker for diagnosis of CES, we found that CRP level was higher in non-CES patients but without any significant difference between CES and non-CES patients (Table 1). This is in agreement with Alvarez-Perez and colleagues [25] and Melake and colleagues [26]. They found that CRP levels were higher among the atherosclerotic group compared with those of CES, and this difference possesed a highly statistical significant effect, and contributed these results to the higher degree of inflammation in atherosclerotic stroke subtype.

C-reactive protein has been suggested to promote platelet activation and foam cell generation through macrophage differentiation, and it has been associated with large artery atherotrombotic events [11].

On the contrary, Kuwashiro and colleagues [27] who worked in a multicenter, prospective cohort research in which acute stroke patients are enroled within 7 days of onset reported that CRP was elevated among CES patients. This elevation of CRP is strongly associated with stroke recurrence in patients with cardio-embolic stroke. Their results could be explained by the larger number of patients included and the longer duration of blood sampling.

There was a non-significant difference between both patient groups regarding G/A ratio, and this was in accordance with Llombart and colleagues [28]. These results could be explained by low albumin level that occurs in many IS subtypes; this lowered albumin level was associated with inflammation and endothelial damage which are common among different stroke etiologies making this biomarker unspecific for differentiating between ischemic stroke subtypes.

On the other hand, Zecca and colleagues [11] postulated that G/A ratio was higher in CES than other IS subtypes and G/A ratio correlates with blood viscosity, being a high ratio associated with increased blood viscosity that occurs in cardio-embolic stroke.

In the current study, BNP higher levels were found in patients with poor short-term outcome as assessed by the modified Rankin scale (mRS) but this role is found to have a statistically non-significant effect with a cutoff value of $\geq 89 \mathrm{pg} / \mathrm{ml}$, while Rost and colleagues [29] and Garcia-Berrocoso and colleagues [30] found that the risk 
Table 3 The serum biomarkers levels and the short-term outcome of cardio-embolic stroke patients as assessed by mRS

\begin{tabular}{|c|c|c|c|c|}
\hline Biomarker & Poor outcome and death $(n=32)$ & Good outcome $(n=16)$ & $t$ test & $p$ \\
\hline \multicolumn{5}{|l|}{ BNP } \\
\hline Mean \pm SD $(p g / m l)$ & $148.09 \pm 107.68$ & $109.3 \pm 36.71$ & -0.301 & 0.763 \\
\hline \multicolumn{5}{|l|}{ CK-MB } \\
\hline Mean \pm SD $(\mathrm{ng} / \mathrm{ml})$ & $1.77 \pm 0.51$ & $1.27 \pm 0.63$ & 2.93 & $0.005^{*}$ \\
\hline \multicolumn{5}{|l|}{ D-Dimer } \\
\hline Mean \pm SD $(n g / m l)$ & $704.39 \pm 271.35$ & $412.53 \pm 151.27$ & 4.762 & $<0.001^{* *}$ \\
\hline \multicolumn{5}{|l|}{ CRP } \\
\hline Mean $\pm S D(m g / l)$ & $34.77 \pm 28.77$ & $15.4 \pm 12.58$ & $(-2.391)$ & $0.020^{*}$ \\
\hline \multicolumn{5}{|l|}{ G/A ratio } \\
\hline Mean \pm SD & $0.73 \pm 0.03$ & $0.71 \pm 0.04$ & 1.705 & 0.095 \\
\hline
\end{tabular}

$m R S$ modified Rankin scale, $B N P$ brain natriuretic peptide, $C K-M B$ creatine-kinase, $C R P$ C-reactive protein, $G / A$ globulin/albumin

**Statistically highly significant

*Statistically significant

of poor functional recovery at 3 and 6 months after stroke could be predicted with higher levels of BNP and pro-BNP. Also Shibazaki and colleagues [20] demonstrated that plasma BNP level $240 \mathrm{pg} / \mathrm{ml}$ on admission can predict in-hospital death in patients with CES.

We found a highly significant positive correlation between stroke outcome as defined by the mRS score and D-dimer levels which increased with poor outcome of CES. D-Dimer above $570 \mathrm{ng} / \mathrm{ml}$ can predict the poor short-term outcome. These results were in accordance with the findings of other studies $[6,31,32]$. On the other hand, Park and colleagues [33] concluded that Ddimer and other markers of hemostatic activation were not associated with stroke progression, recurrent stroke, or death in patients with acute stroke and AF.

In our study, we found that high levels of CK-MB had a significant role in predicting the poor outcome of CES patients with a cutoff level of $\geq 1.15 \mathrm{ng} / \mathrm{ml}$ in prediction of poor short-term outcome of CES. These results goes in hand with other studies $[34,35]$ who found that cardiac enzymes including CK-MB, tropnin $\mathrm{T}$, and myoglobin are elevated in CES especially with right hemisheric lesion and related to poor outcome at 30-day follow-up.

It is clear that high-sensitivity CRP has an important role in the prognosis and risk factor of prediction in stroke diseases, including long-term and short-time death risk, early diagnosis, prediction of etiological subtypes, and prognosis
[36]. Other studies have demonstrated that high hs-CRP was an independent predictor of long-term mortality in patients with stroke $[37,38]$.

A multivariant analysis was done for the predictors of good and poor short-term outcome of cardio-embolic

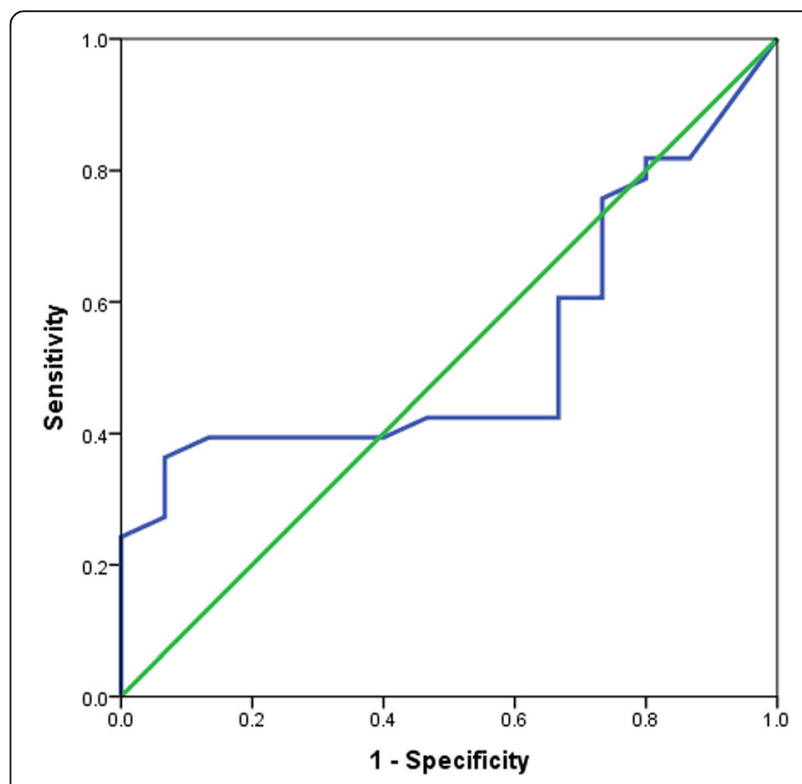

Fig. 4 ROC curve showing performance of BNP in prediction of poor outcome

Table 4 The performance of different biomarkers in the prediction of poor short-term outcome in cardio-embolic stroke

\begin{tabular}{lllllllll}
\hline Biomarker & Cutoff & AUC & Sensitivity & Specificity & PPV & NPV & Accuracy & $p$ \\
\hline BNP & 89 & 0.527 & 57.6 & 33.3 & 65.5 & 26.3 & 50 & 0.764 \\
D-Dimer & 570 & 0.791 & 90.9 & 66.3 & 81.8 & 72.7 & 79.2 & $0.001^{*}$ \\
CK-MB & 1.15 & 0.732 & 84.8 & 60 & 82.4 & 64 & 77.1 & $0.011^{*}$ \\
CRP & 25.5 & 0.710 & 60.6 & 60 & 76.9 & 40.9 & 60.4 & $0.021^{*}$ \\
\hline
\end{tabular}

$B N P$ brain natriuretic peptide, $C K-M B$ creatine-kinase, $C R P$ C-reactive protein, $P P V$ positive predictive value, NPV negative predictive value *Statistically significant 


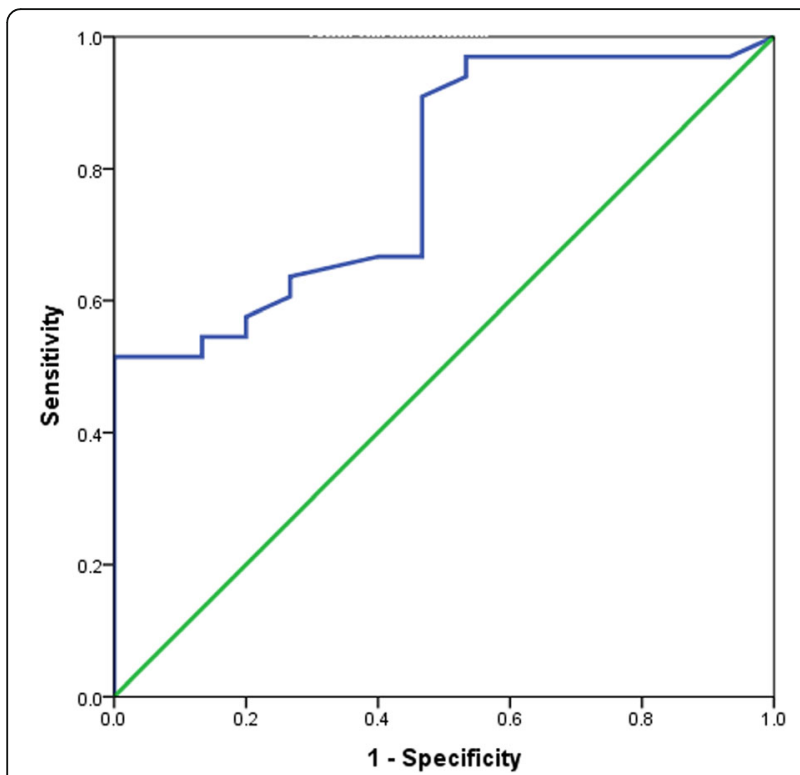

Fig. 5 ROC curve showing performance of D-dimer in prediction of poor outcome

stroke. We noticed that low GCS and elevated CK-MB were the most important predictors of poor short-term outcome of CES patients at the third week as assessed by $\mathrm{mRS}$.

These results were in accordance with studies [39, 40] who assumed that disturbed consciousness at admission which correspond to low GCS was the powerful predictor of poor short outcome. We found that high GCS and low NIHSS at admission are the best predictors of good outcome. These results are the same of others $[41,42]$, who

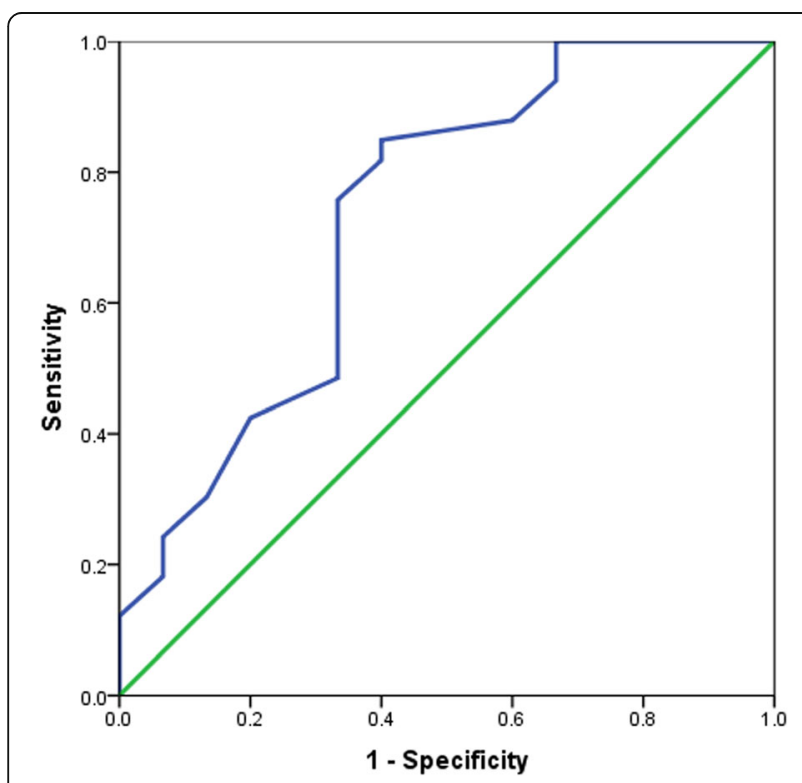

Fig. 6 ROC curve showing performance of CK-MB in prediction of poor outcome

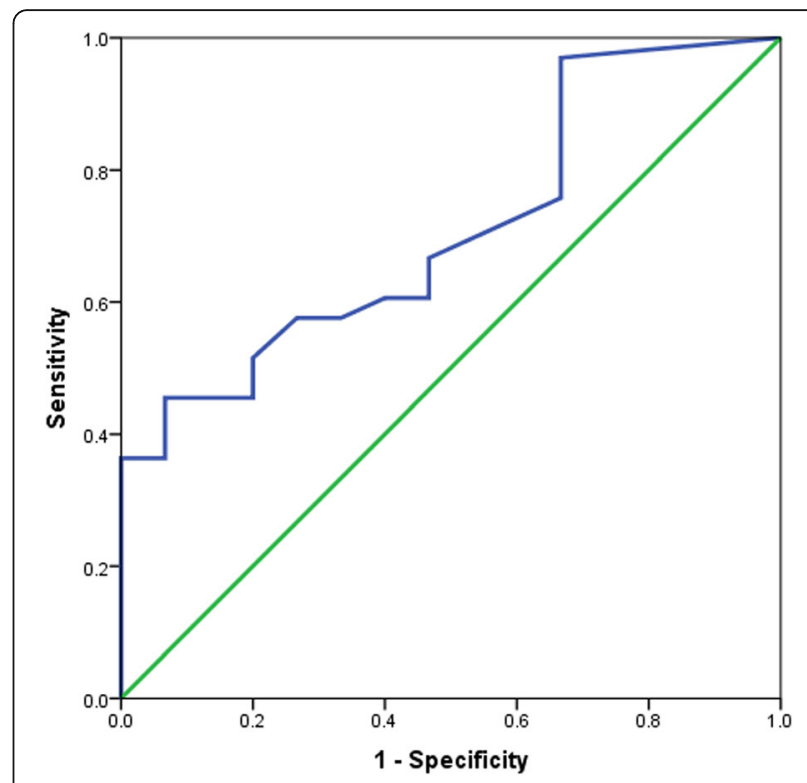

Fig. 7 ROC curve showing performance of CRP in prediction of poor outcome

concluded that an NIHSS score of $\leq 15$ is an independent predictor of good prognosis in their studies.

Mansour and colleagues [43] in their study concluded that the GCS and the four scores are accurate predictors of good outcome after different acute ischemic stroke subtypes and are equal in prediction to the NIHSS.

\section{Conclusion}

Our study supports the role of BNP, D-Dimer, and CK$\mathrm{MB}$ in the diagnosis and prediction of the short-term outcome of cardio-embolic stroke. Moreover, it was concluded that low GCS and elevated CK-MB were the most important predictors of poor short-term outcome of CES patients, whereas high GCS and low NIHSS at admission are the best predictors of good outcome role.

Table 5 The clinical and laboratory predictors of poor shortterm outcome in cardio-embolic stroke patients

\begin{tabular}{lllll}
\hline Predictor & B & OR & Cl & $p$ \\
\hline GCS at admission & -2.339 & 0.096 & $(0.008-1.184)$ & $0.052^{*}$ \\
NIHSS at admission & -0.183 & 0.833 & $(0.367-1.888)$ & 0.661 \\
BNP & -0.019 & 0.981 & $(0.950-1.013)$ & 0.236 \\
D-Dimer & 0.005 & 1.005 & $(0.988-1.023)$ & 0.540 \\
CK-MB & -1.543 & 0.214 & $(0.004-11.152)$ & $0.044^{*}$ \\
CRP & -0.19 & 0.982 & $(0.871-1.106)$ & 0.761 \\
\hline
\end{tabular}

GCS Glasgow Coma Scale, NIHSS National Institutes of Health Stroke Scale, BNP brain natriuretic peptide, $C K-M B$ creatine-kinase, CRP C-reactive protein *Statistically significant 
Table 6 Clinical and laboratory findings as a predictors of good outcome in cardio-embolic stroke patients

\begin{tabular}{llll}
\hline Predictor & OR & $\mathrm{Cl}$ & $p$ \\
\hline GCS at admission & 30.814 & $(1.765-538.013)$ & $0.019^{*}$ \\
NIHSS at admission & 0.457 & $(0.318-0.656)$ & $<0.001^{* *}$ \\
BNP & 0.986 & $(0.96-1.012)$ & 0.284 \\
D-Dimer & 1.027 & $(0.955-1.004)$ & 0.362 \\
CK-MB & 0.979 & $(0.722-1.044)$ & 0.104 \\
CRP & 0.892 & $(0.761-1.044)$ & 0.155
\end{tabular}

GCS Glasgow Coma Scale, NIHSS National Institutes of Health Stroke Scale, BNP brain natriuretic peptide, $C K-M B$ creatine-kinase, CRP C-reactive protein **Statistically highly significant

*Statistically significant

\section{Recommendation}

We recommend further studies with larger sample size and longer duration of follow-up for better outcome assessment and combining these biomarkers with advanced cardiological investigations for better assessment of their role.

\section{Abbreviations}

BNP: Brain natriuretic peptide; CES: Cardio-embolic stroke; Cl: Confidence intervals; CK-MB: Creatine-kinase; CRP: C-reactive protein; G/A: Globulin/ albumin; GCS: Glasgow Coma Scale; IS: Ischemic strokes; mRS: Modified Rankin scale; NIHSS: National Institutes of Health Stroke Scale; OR: Odds ratios; TIAs: Transient ischemic attacks

\section{Acknowledgements}

An acknowledgement is not applicable in this section.

\section{Authors' contributions}

EAA, ASE, WSM, and SEF carried out this work. EAA designed the study, had done the statistical analysis, and wrote the manuscript. EAA, ASE, and WSM did the literature search and coordinated the research team. ASE, WSM, and SEF collected the patients, gathered the clinical data, and reviewed the manuscript. All authors were involved in drafting the article or revising it critically for important intellectual content, and all authors approved the final version to be published.

\section{Funding}

There is no source of funding for the research.

\section{Availability of data and materials}

Data and materials supporting the results of this article are included within the article (and its additional file(s)).

\section{Ethics approval and consent to participate}

The study was approved by the institutional ethics committee of the faculty of medicine, Zagazig University (ZU-IRB\#: 2325/7-9-2015). A written consent was taken from all the participants after explaining the details, benefits, and risks to them.

\section{Consent for publication}

Consent for publication has been obtained from the participants involved in the study to report their individual patient data.

\section{Competing interests}

The authors declare that they have no competing interests.

Received: 18 January 2019 Accepted: 6 August 2019

1.

\section{References}

1. Go AS, Mozaffarian D, Roger VL, Benjamin EJ, Berry JD, Blaha MJ, et al. American Heart Association Statistics Committee and Stroke Statistics
Subcommittee. Heart disease and stroke statistics-2014 update: a report from the American Heart Association. Circulation. 2014;129:e28-e292. https://doi.org/10.1161/01.cir.0000441139.02102.80.

2. Sorensen $A G, A y H$. Transient ischemic attack: definition, diagnosis, and risk stratification. Neuroimaging Clin N Am. 2011;21:303-13, x. https:// doi.org/10.1016/j.nic.2011.01.013.

3. O'Carroll CB, Barrett KM. Cardioembolic stroke. Cerebrovasc Dis. 2017;23(1):111-32.

4. Sazonova I, Pondicherry-Harish R, Kadle N, Sharma G, Figueroa R, Robinson $\mathrm{V}$. Embolic stroke diagnosed by elevated $\mathrm{D}$-dimer in a patient with negative TEE for cardioembolic source. J Med High Impact Case Rep. 2014;14:1-4.

5. Preethi B, Ramakrishna C, Roopa M, Rao S. Serum creatine kinase MB in ischemic stroke: a case control study. J Evolution Med Dent Sci. 2016; 5(52):3386-90.

6. Zi W-J, Shuai J. Plasma D-dimer levels are associated with stroke subtypes and infarction volume in patients with acute ischemic stroke. PLoS One. 2014;9(1):1-8.

7. Montaner J, Mendioroz M, Ribó M, Delgado P, Quintana M, Penalba A, et al. A panel of biomarkers including caspase- 3 and D-dimer may differentiate acute stroke from stroke-mimicking conditions in the emergency department. J Intern Med. 2011;270(2):166-74.

8. Maruyama K, Shiga T, lijima M, Moriya S, Mizuno S, Toi S, et al. Brain natriuretic peptide in acute ischemic stroke. J Stroke Cerebrovasc Dis. 2014; 23(5):967-72.

9. Mohanapriya P, Sudharsan S, Sathishkumar JT. Significance of cardiac enzymes in patients with acute stroke. J Med Sci clin Res. 2017;5(10):29026-9.

10. Lip GY, Lim HS. Atrial fibrillation and stroke prevention. Lancet Neurol. 2007;6:981-93.

11. Zecca B, Mandelli C, Maino A, Casiraghi C, Bolla G, Dario Consonni D, et al. A bio clinical pattern for the early diagnosis of cardio-embolic stroke. Emerg Med Int. 2014;14:e242171.

12. Adams HP, Bendixen BH, Kappelle LJ, Biller J, Love BB, Gorden DL, et al. Classification of subtypes of acute ischaemic stroke: definition for use in a multicenter clinical trial. Stroke. 1993;24:35-41.

13. Jennett B. The Glasgow coma scale: history and current practice. Trauma. 2002;4(2):91-103.

14. Fonarow GC, Saver JL, Smith EE, Broderick JP, Kleindorfer DO, Sacco RL, et al. Relationship of National institutes of health stroke scale to 30-day mortality in medicare beneficiaries with acute ischemic stroke. J Am Heart Assoc. 2012;1:42-50.

15. Yasue $H$, Yoshimura M, Sumida H, Kikuta K, Kugiyama K, Jougasaki M, et al. Localization and mechanism of secretion of B-type natriuretic peptide in comparison with those of A-type natriuretic peptide in normal subjects and patients with heart failure. Circulation. 1994;90(1):195-203.

16. Sarhan N, Zaitoun MA, Abdel Ghani A, Ashour W. The association between plasma D-dimer levels and stroke (subtypes, severity and size ) in Zagazig university hospitals MSc.Thesis.Zagazig University; 2015.

17. Ay H, Arsava EM, Sarıbas O. Creatine kinase-MB elevation after stroke is not cardiac in origin comparison with troponin T levels. Stroke. 2002;33:286-9.

18. Giantin V, Semplicini A, Franchin A, Simonato M, Baccaglini K, Attanasio F, et al. Outcome after acute ischemic stroke (AIS) in older patients: effects of age, neurological deficit severity and blood pressure (BP) variations. Arch Gerontol Geriat. 2010;52(3):185-91.

19. Levesque R. SPSS programming and data management: a guide for SPSS and SAS users. 4th ed. Chicago III: SPSS Inc; 2007.

20. Shibazaki K, Kimura K, Okada Y, Iguchi Y, Uemura J, Terasawa Y, et al. Plasma brain natriuretic peptide as an independent predictor of in-hospital mortality after acute ischemic stroke. Intern Med. 2009;48(18):1601-6.

21. Doufekias E, Segal AZ, Kizer JR. Cardiogenic and aortogenic brain embolism. J Am Coll Cardiol. 2008;51:1049-59.

22. Abd-Elhamid YA, Tork MA, Abdulghani MO. Prognostic value of D-dimer measurement in patients with acute ischemic stroke. Egypt J Neurol Psychiat Neurosurg. 2016;53:146-50.

23. Santamarina E, Penalba A, Garcı-Berrocoso T, Delgado P. Biomarker level improves the diagnosis of embolic source in ischemic stroke of unknown origin. J Neurol. 2004;259(12):2538-52.

24. Rodríguez-Yáñez M, Sobrino T, Blanco M, De la Ossa NP, Brea D, Rodríguez $\mathrm{R}$, et al. High serum levels of pro-brain natriuretic peptide (pro BNP) identifies cardio-embolic origin in undetermined stroke. Dis Markers. 2009; 26(4):189-95.

25. Alvarez-Perez FJ, Castelo-Branco M, Alvarez-Sabin J. Usefulness of measurement of fibrinogen, D-dimer, D-dimer/fibrinogen ratio, $\mathrm{C}$ reactive protein and 
enthrocyte sedimentation rate to assess the pathophysiology and mechanism of ischemic stroke. J Neurol Neurosurg Psychiatry. 2011;82:986-92.

26. Melakea MS, El-Kabany RA, Al-Emam AK, El-Shereef AM, Okdaa M. The role of D-dimer, fibrinogen and C-reactive protein as plasma biomarkers in acute ischemic stroke. J Neurol Res. 2015;5(6):277-82.

27. Kuwashiro T, Sugimori H, Ago T, Kuroda J, Kamouchi M, Kitazono T. Predictive role of $\mathrm{C}$ reactive protein in stroke recurrence after cardio-embolic stroke : the Fukuoka stroke registry. Bio Med J Open. 2013;3(11):003678.

28. Llombart V, Garcia-Berrocoso T, Bustamante A, Fernandez-Cadenas I, Montaner J. Cardio-embolic stroke diagnosis using blood biomarkers. Curr Cardiol Rev. 2013;9(4):340-52.

29. Rost NS, Biffi A, Cloonan L, Chorba J, Kelly P, Greer D, et al. Brain natriuretic peptide predicts functional outcome in ischemic stroke. Stroke. 2012;43:441-5.

30. Garcia-Berrocoso T, Giralt D, Bustamante A, Etgen T, Jensen JK, Shamia J, et al. B-type natriuretic peptide and mortality after stroke. Neurology. 2013; 81(23):1976-85.

31. Meng R, Li ZY, Ji X, Ding Y, Meng S, Wang X. Anti-thrombin III associated with fibrinogen predicts the risk of cerebral ischemic stroke. Clin Neurol Neurosurg. 2011;113(5):380-6.

32. Abdel Ghani AA, Zaitoun AM, Gawish HH. Prognostic value of D-dimer in diffusion weighted-MRI defined early ischemic stroke recurrence. Egypt J Neurol Psychiat Neurosurg. 2011;48(3):215-22.

33. Park YW, Koh EJ, Choi HY. Correlation between serum Ddimer level and volume in acute ischemic stroke. J Korean Neurosurg Soc. 2011;50(2):89-94.

34. Liu L, Wang D, Wong KS, Wang Y. Stroke and stroke care in China: huge burden, significant workload, and a national priority. Stroke. 2011:42:3651-4.

35. Kim BJ, Kang HG, Kim HJ, Ahn SH, Kim NA, Warach S, et al. Magnetic resonance imaging in acute ischemic stroke treatment. Stroke. 2014;16(3):131-45.

36. Yu H, Huang Y, Chen X, Nie W, Wang Y, Jiao Y, et al. High-sensitivity C-reactive protein in stroke patients - the importance in consideration of influence of multiple factors in the predictability for disease severity and death. J Clin Neurosci. 2016;36:12-9.

37. Yeh KH, Tsai TH, Chai HT, Leu S, Chung SY, Chua S, et al. Comparison of acute versus convalescent stage high-sensitivity C-reactive protein level in predicting clinical outcome after acute ischemic stroke and impact of erythropoietin. J Transl Med. 2012;10:6-11.

38. Xie D, Deng L, Liu XD, Li JM, Zhang YB. Role of high sensitivity C-reactive protein and other risk factors in intracranial and extracranial artery occlusion in patients with ischemic stroke. J Int Med Res. 2015;43(5):711-7.

39. Angelantonio E, Fiorelli M, Toni D, Sacchetti ML, Lorenzano S, Falcou A, et al. Prognostic significance of admission levels of troponin I in patients with acute ischemic stroke. Neurol Neurosurg Psychiatry. 2005;76:76-81.

40. Bill O, Zufferey P, Faouzi M, Michel P. Severe stroke: patient profile and predictors of favorable outcome. J Thromb Haemost. 2013;11:92-9.

41. Castillo J, Leira R. Predictors of deteriorating cerebral infarct: role of inflammatory mechanisms. Would its early treatment be useful? Cerebrovasc Dis. 2001;11(1):40-8.

42. Tei SH, Uchiyama T, Usui M. Predictors of good prognosis in total anterior circulation infarction within $6 \mathrm{~h}$ after onset under conventional therapy. Acta Neurologica. 2006;113(5):301-6.

43. Mansour OY, Megahed MM, Abd Elghany EH. Acute ischemic stroke prognostication, comparison between Glasgow Coma Score, NIHS scale and full outline of unresponsiveness score in intensive care unit. Alexandria J Med. 2015;51(3):247-53.

\section{Publisher's Note}

Springer Nature remains neutral with regard to jurisdictional claims in published maps and institutional affiliations.

\section{Submit your manuscript to a SpringerOpen ${ }^{\circ}$ journal and benefit from:}

- Convenient online submission

- Rigorous peer review

- Open access: articles freely available online

High visibility within the field

- Retaining the copyright to your article

Submit your next manuscript at $\boldsymbol{\nabla}$ springeropen.com 